\title{
Syncope in Childhood: A Case Control Clinical Study of the Familial Tendency to Faint
}

\author{
Peter R. Camfield and Carol S. Camfield
}

\begin{abstract}
We investigated the possibility of an inherited tendency to faint by studying 30 consecutively referred well children with vasodepressor or vasovagal syncope. The family history of each patient was reviewed for syncope and for 24 cases was compared with the family history of the child's best friend. None of the best friends had syncope. $27 / 30$ cases and $8 / 24$ best friends had at least one first degree relative with syncope $(p<0.01)$. Of the 8 best friend controls with a parent or sibling with syncope, the mother was affected in 7; 4/7 of these mothers had first degree relative(s) with syncope. In 11/30 patients both a sibling and parent had syncope compared with 1/24 of control families $(p<.01)$. We conclude that there is an inherited tendency to faint since most children who faint have a first degree relative who faints, a useful fact in differential diagnosis. This inherited tendency may be multifactorial but requires an environmental stimulus for expression.

RÉSUMÉ: Syncope dans l'enfance: une étude clinique cas-témoin sur la tendance familiale à la lipothymie Nous avons investigué la possibilité qu'il existe une tendance héréditaire à la syncope en étudiant 30 cas consécutifs d'enfants en bonne santé référés pour syncope vasovaguale ou par collapsus circulatoire. L'histoire familiale de chaque patient a été révisée en ce qui concerne la syncope. Pour 24 des cas, cette histoire familiale a été comparée à celle du meilleur ami de l'enfant. Aucun des contrôles n'avait de syncope. Vingt-sept cas sur 30 et 8 contrôles sur 24 avait au moins un parent au premier degré qui présentait des syncopes $(\mathrm{p}<0.01)$. Des 8 contrôles qui avaient un parent ou un membre de la fratrie avec syncopes, chez 7 la mère était le parent atteint; 4 parmi ces 7 mères avaient un parent au premier degré qui avait des syncopes. Chez 11 des 30 patients, un membre de la fratrie et un parent présentaient également des syncopes, comparé à 1 sur 24 chez les families contrôles $(p<0.01)$. Nous concluons qu'il existe une tendance héréditaire à la lipothymie parce que la plupart des enfants qui ont des syncopes ont un parent au premier degré qui a également des syncopes, un fait utile au diagnostic différentiel. Cette tendance héréditaire peut être multifactorielle, mais requière un stimulus environnemental pour son expression.
\end{abstract}

Can. J. Neurol. Sci. 1990, 17:306-308

Vasovagal and vasodepressor syncope are relatively common in childhood and adolescence. ${ }^{1}$ Loss of consciousness results from a drop in systemic blood pressure and peripheral resistance without compensatory tachycardia. The physiology of these disorders has received extensive investigation, but little has been published about the predisposing characteristics of children who faint. ${ }^{2}$ Knowledge of such factors would be helpful in the differential diagnosis of syncope, especially in distinguishing it from epilepsy.

It is our hypothesis that although in most people fainting can be induced by sufficient stress, the tendency to faint or "the syncope threshold" is influenced by hereditary factors. We report a controlled study of the incidence of syncope among close family members of children who faint.

\begin{abstract}
METHOD
Consecutive outpatients referred to 2 pediatric neurologists were reviewed. Patients were accepted with a clearcut clinical history of vasovagal or vasodepressor syncope where the general physical and neurological examinations were normal and there was no close family history of sudden unexpected death. Clinical features necessary for the diagnosis of syncope were precipitating events such as pain or long periods of time standing in one place, typical premonitory symptoms, loss of consciousness, pallor, limpness, and prompt recovery of consciousness. No attempt was made to clearly distinguish in each case between vasovagal and vasodepressor syncope. In no case was the patient exercising at the time of the syncope. Breath holding and pallid syncope were excluded. Diagnostic confusion
\end{abstract}

From the Department of Pediatrics, Dalhousie University, Izaak Walton Killam Hospital for Children, Halifax, Nova Scotia Received January 8, 1990. Accepted April 4, 1990

Presented in part at the Canadian Congress of Neurological Sciences, Vancouver, British Columbia, June 1987

Reprint requests to: Dr. P. Camfield, Izaak Walton Killam Hospital for Children, Box 3070, Halifax, Nova Scotia, Canada B3J 3G9 
between pallid syncope and vasovagal syncope in children under 4 years of age was lessened by excluding pain as a precipitant for this age group only. The histories were sufficiently characteristic that laboratory investigations were not carried out in most patients.

Each family was then contacted by telephone to review the family history and obtain the name of the child's same sex, same age best friend. This control child's family was then contacted by telephone and questioned about syncope both for the best friend and other family members including first and second degree relatives. First degree relatives were considered to be parents and siblings; second degree relatives were grandparents, aunts and uncles. When the respondent was unsure of the family history a followup call was made after 7 days. An attempt was made in all controls to confirm the clinical historical circumstances of fainting events using the criteria listed above. Cases were not accepted if there were other disorders likely to cause loss of consciousness such as epilepsy, stroke or known heart disease. Control families with a history of sudden unexpected death were excluded. Because the information about family members at times involved recall of events that had occurred some time previously, it was difficult to be certain of the exact number of fainting episodes for some family members except for our patients. Therefore, in any individual a single convincing episode of vasovagal or vasodepressor syncope was considered positive for fainting.

Statistical comparisons between those with and without syncope were carried out using $2 \times 2$ tables and chi-squared analysis. Significant results were defined as $p<0.05$.

\section{Results}

Thirty-seven patients with syncope were identified during the study period. Six were lost to followup and one child was adopted leaving 30 cases for study. There were 8 boys and 22 girls with an average age of 10 years (range 2-15 years) and median age of 12 years. The number of syncopes in our patients averaged 4 per patient with a range of one to greater than 20 syncopes per patient; 2 of our patients had only 1 syncopal episode while 2 reported greater than 20 episodes.

$27 / 30$ ( 8 boys and 19 girls) patients had at least one first degree relative with syncope. At least one of the affected relatives was a parent of the child in 26 (Table 1). In one case a sibling was the only other first degree relative with syncope. Of the 60 patents of patients with syncope 31 had fainted $(23$ mothers and 8 fathers). The syncope patients had 64 siblings (32 sisters and 32 brothers) of whom $17(26.6 \%)$ had fainted. This included $14(43.8 \%)$ sisters and $3(9.3 \%)$ brothers.

Table 1: Summary of Results

\begin{tabular}{lcc}
\hline & Patients $\mathbf{n}=\mathbf{3 0}$ & Controls = 24 \\
\hline $\begin{array}{l}\text { At least } 1 \text { first } \\
\text { degree relative }\end{array}$ & $27(31 / 60$ parents & $8(7 / 48$ parents \\
with syncope & $17 / 64$ sibs $)$ & $2 / 34$ sibs $)^{*}$ \\
$\begin{array}{l}\text { Sib + parent } \\
\text { with syncope }\end{array}$ & $11 / 30$ & $1 / 24^{* *}$ \\
\hline$* \quad p<0.01$. & & \\
$* * 0.05$. & & \\
$p$ & & \\
& &
\end{tabular}

For 24 of the cases an appropriate control family was available. None of the best friends had themselves fainted. $8 / 24$ control best friends had a first degree relative who had fainted which is significantly less than the rate in patients' first degree relatives (chi square $=15.5, \mathrm{p}<0.01$ ). For $7 / 8$ of the control children with a first degree relative who had fainted, the relative who had fainted was the child's mother. $4 / 7$ of these mothers themselves had a parent or sibling who had fainted. Therefore, in only $2 / 24$ control children was there a first degree relative who had fainted and no other family history of fainting. Overall, the patients who had a matched control had 43 siblings and the controls had 34 siblings.

In 11/30 syncope patients both a parent and a sibling had fainted. This combination was noted in only 1/24 controls (chi squared, $\mathrm{p}<.05$ ).

\section{Conclusions}

We have found that virtually all children who faint have a first degree relative (usually a parent) with a history of syncope. Among control families, fainting was significantly less common and, when it did occur, first degree relatives of the person who had fainted usually also had fainted. Only rarely did we encounter someone who had fainted without a first degree relative with a similar history.

Our number of cases is too small and our family histories cover insufficient generations to establish the specific genetic basis for fainting. This study might suggest that the tendency to faint is inherited as an autosomal dominant with a high degree of penetrance. Simple autosomal dominant transmission would not explain the well known excess of women with syncope compared with men that we also observed. ${ }^{1}$

It is more likely that the genetic basis for the tendency to faint is multifactorial. The tendency to faint is presumably related to regulation of blood pressure. Arterial blood pressure is thought to be determined by a combination of multiple genelic influences plus environmental factors and is therefore said to be multifactorial. ${ }^{3}$ Blood pressure in children resembles that of their parents - no single factor explains this association. ${ }^{4}$ Syncope results from faulty blood pressure control and is the final result of several mechanisms including bradycardia from excessive vagal discharge and/or lack of sympathetic tone. 5 Therefore, the inheritance of the tendency to faint may be polygenic and more readily expressed in women when there is an adequate environmental stimulus.

Autosomal dominant familial cardiac causes of "syncope" are well described. 6 We attempted to exclude such rare disorders as prolonged QT interval by excluding families with a history of sudden death and by insisting on a typical history of vasovagal or vasodepressor syncope. No detailed cardiac rhythm studies were carried out. Gordon et al have noted that extensive evaluation of children with a clear history of fainting only very rarely yields an alternate diagnosis. ${ }^{7}$ Thus it is unlikely that any of our patients' vasodepressor or vasovagal syncopes diagnosed by history were the result of unsuspected cardiac disease. A possible weakness in our study design is the potential for recall bias in the parents whose child had fainted. Control parents all appeared confident of their medical histories and when there was uncertainty they were instructed to review the family history and were then called again. Our emphasis on first degree 
relatives reduces recall bias although only a large prospective cohort study could eliminate this problem.

Paroxsymal disorders such as epilepsy may be familial so that a family history alone is obviously not diagnostic of syncope. The practical implication of our study is that the diagnosis of vasovagal or vasodepressor syncope in a child should nearly always be accompanied by a close family history of syncope.

\section{ACKNOWLEDGEMENTS}

Deidre Murphy assisted with the case histories and lone Anderson provided expert secretarial assistance. Dr. David Cole offered valuable suggestions and we thank Dr. John Tibbles for the opportunity to study some of his patients.

\section{REFERENCES}

1. Menkes JH. Textbook of Child Neurology. Philadelphia: Lea \& Febiger $1980 ; 589$.
2. Wayne HH. Syncope - Physiological considerations and an analysis of the clinical characteristics in 510 patients. Am J Med $1961 ; 30: 418-438$.

3. Cruz-Coke R. Genetic aspects of essential hypertension. In: Handbook of Hypertension, vol. 1. Robertson JIS, ed. Elsevier Science Publishers Amsterdam/N.Y.BV 1983.

4. Havlik RJ, Garrison RJ, Feinleib M, et al. Blood pressure aggregation in families. Am J Epidemiol 1979; 110: 304-312.

5. Thomas JE. Diseases of the carotid sinus-syncope. $I n$ : Handbook of Clinical Neurology. Volume II. P.J. Vinken and G.W. Bruyn, eds. American Elsevier Publishers Inc, NY. Ch 19:532-55I.

6. VonBernuth G, Bernsau U, Gutheil $\mathrm{H}$, et al. Tachyarrhythmic syncopes in children with structurally normal hearts with and without QT-prolongation in the electrocardiogram. Eur J Pediatr 1982; 138: 206-210.

7. Gordon TA, Moodie DS, Passalacqua, et al. A retrospective analysis of the cost effective workup of syncope in children. Cleve Clin Q 1987; 54: 391-394. 